\title{
Komparasi Efektivitas dan Model Governance Inkubator Bisnis Digital antara Pengelola Pemerintah, BUMN, Swasta, Komunitas, dan Universitas
}

\author{
Suci Lestari Yuana ${ }^{1}$ \\ Nur Azizah ${ }^{2}$ \\ Indri Dwi Apriliyanti ${ }^{3}$
}

\begin{abstract}
The growing number of incubator business and coworking spaces for digital business in Indonesia has raised critical question on its correlation with Indonesian competitiveness in IT industry. This paper attempts to analyze internal factors of each incubator model that drives innovation as well as to identify power relations of actors in IT ecosystem. In the context of Global Value Chain governance, Indonesian incubation model showed tendencies toward relational governance. The type of relation was complex and interdependent. This condition has pushed the emergence of Godfather actor who had specific competences that sustain innovation.
\end{abstract}

Keywords:

innovation; digital incubators; governance.

\begin{abstract}
Abstrak
Bertambahnya aktor-aktor yang menyediakan layanan inkubasi bisnis digital dan coworking space di kota-kota di Indonesia menimbulkan pertanyaan mengenai korelasi fenomena inkubasi bisnis digital dengan peningkatan daya saing technopreneur Indonesia dan tarik-menarik kepentingan nasional dan global antar aktor. Tulisan ini fokus menganalisa beberapa aspek internal dari strategi aktor penyedia layanan inkubasi dalam merangsang inovasi, lalu posisi aktor dalam rantai nilai global dan juga relasi kekuasaan antar aktor. Konteks governance dalam Global Value Chain, pola relasi antara inkubator dengan startup menunjukkan kecenderungan pada model governance yang relational. Pola hubungan berlangsung secara kompleks sehingga terjalin ketergantungan antara kedua belah pihak. Hal ini kemudian membuat startup membutuhkan Godfather, yang merupakan aktor dengan kapasitas tertentu yang dapat digunakan untuk memastikan inovasi dapat berjalan.
\end{abstract}

\section{Kata kunci:}

inovasi; inkubasi digital; governance.

\footnotetext{
1 Dosen Departemen Hubungan Internasional FISIPOL UGM.

Email: sl.yuana@gmail.com

2 Dosen Departemen Politik dan Pemerintahan FISIPOL UGM.

3 Dosen Departemen Manajemen dan Kebijakan Publik FISIPOL UGM.
} 


\section{Pendahuluan}

Inovasi dalam industri TI menjadi hal yang penting untuk dikembangkan. Tidak terkecuali di Indonesia, dimana jumlah pengguna internet pada tahun 2013 telah mencapai angka 82 juta atau sekitar 30 persen dari total penduduk dan nilai transaksi $e$-commerce tahun 2014 mencapai Rp130 triliun. Jumlah tersebut akan terus meningkat setiap tahunnya. Kesempatan ini kemudian mendorong berbagai aktor untuk ikut bergerak dalam mengembangkan inovasi dalam bisnis TI di Indonesia. Aktor tersebut terdiri dari pemerintah, swasta, universitas, ataupun komunitas. Proses pengembangan inovasi dihadirkan dengan membuat program berupa coworking space, inkubator bisnis, maupun akselerator bisnis.

Bertambahnya aktor-aktor yang menyediakan layanan coworking space di kotakota di Indonesia menjadi fokus studi yang menarik. Kajian mengenai perbedaan model inkubasi yang dikembangkan oleh aktor yang berbeda, yakni pemerintah (BUMN via Telkom), private sector yang terdiri dari investor lokal dan investor asing serta komunitas lokal menjadi menarik untuk diteliti lebih lanjut, terutama dengan menganalisa strategi positioning setiap aktor dalam rantai nilai global/Global Value Chain(GVC) serta bentuk power relations yang terjadi baik secara horizontal di antara aktor yang menyediakan layanan inkubasi maupun secara vertikal di antara aktor, target pasar, investor, dan pemerintah.

Secara umum, fenomena ini dapat dikaji dari berbagai perspektif, antara lain jaringan kerja para aktor di dalam inkubasi bisnis, determinan efektivitas inkubasi bisnis, dan pola relasi kuasa antar aktor di dalam inkubasi bisnis. Berbagai perspektif ini saling terkait satu sama lain sehingga kajiannya dapat dilaksanakan secara integratif.

Berdasarkan beberapa poin penting tersebut, tulisan ini akan mencoba menjawab beberapa pertanyaan berikut:
1. Seberapa besar efektivitas tiap inkubasi bisnis yang diinisiasi oleh aktor-aktor yang berbeda?

2. Bagaimana pola relasi kekuasaan antar aktor dalam ekosistem industri digital?

\section{Metode dan Lokasi Penelitian}

Metodologi penelitian yang digunakan dalam penelitian ini adalah metodologi penelitian kualitatif. Metodologi penelitian kualitatif digunakan untuk mencari, mengumpulkan, mengolah, dan menganalisis hasil penelitian. Format desain penelitian kualitatif yang ditawarkan adalah format verifikasi dengan desain logika deduksihipotesis-verifikasi. Format desain dalam penelitian kualitatif sebenarnya terdiri dari tiga model, yaitu format deskriptif, format verifikasi, dan format grounded research. Desain penelitian verifikatif digunakan karena titik tekannya yang strategis dalam kerangka kajian klaster industri TI ini. Dalam penggunaan desain verifikatif, peneliti akan terjun ke lapangan dengan membawa hipotesis-hipotesis yang akan diverifikasi melalui serangkaian wawancara mendalam dan FGD dengan para aktor yang menjadi objek penelitian.

Pemilihan kota dilakukan berdasarkan ketersediaan klaster industri TI di Indonesia. Pengembangan klaster industri TIyang diinisiasi dan dikelola oleh pemerintah yakni BUMN Telkom berada di Kota Jakarta, Bandung, dan Yogyakarta; klaster industri TI yang diinisiasi dan dikelola oleh pihak komunitas lokal dan investor asing berada di Kota Denpasar. Unit analisis yang akan dibahas di dalam penelitian ini adalah beberapa model inkubator dan akselerator bisnis yang tersebar di tiga kota: seperti model pengembangan inovasi yang dilakukan oleh pemerintah diantaranya dilakukan oleh BPPT dan Kominfo. PT Telkom Tbk sebagai BUMN juga mengembangkan dua inkubator bisnis di Bandung Digital Valley (Bandung), Jogja Digital Valley (Yogyakarta), dan akselerator bisnis Jakarta Digital Valley. 
Model pengembangan yang dilakukan oleh swasta ditangani oleh inkubasi bisnis seperti Merah Putih Incorporation (Jakarta) dan PT Kolaborasi Kapital Indonesia (Bandung). Sedangkan model pengembangan inkubasi bisnis yang dilakukan oleh universitas di antaranya adalah Lembaga Pengembangan Inovasi dan Kewirausahaan (ITB), Innovative Academy (UGM), Skystar Venture (UMN), dan Binus Creates (Binus). Model coworking space yang dikembangkan oleh swasta di antaranya adalah Co\&Co (Bandung), Conclave (Jakarta), Hackerspace (Bandung), dan Maliome Hackerspace (Bandung). Gy uio'

\section{Profil Inkubator dan Coworking Space di Jakarta, Bandung dan Yogyakarta}

\section{a. Model BUMN: PT Telkom Tbk}

Telkom memiliki program pengembangan startup yang berbasis pada bidang digital. Program pengembangan ini diterjemahkan dalam pembuatan tiga entitas pengembang, yakni akselerator bisnis, inkubator bisnis, dan coworking space. Akselerator bisnis berlokasi di Jakarta dan bernama Jakarta Digital Valley, inkubator bisnis beserta coworking space berlokasi di Bandung dan Yogyakarta, bernama Bandung Digital Valley serta Jogjakarta Digital Valley. Sesuai dengan kategori entitas yang dibentuk oleh Telkom, akselerator bisnis, inkubator bisnis, dan coworking space memiliki layanan yang berbeda bagi startup digital yang berada di bawah naungan entitasnya; jika akselerator bisnis dan inkubator bisnis menyediakan layanan dan sumberdaya bisnis yang dibutuhkan oleh startup digital, maka coworking space hanya berperan dalam menyediakan ruangan dan fasilitas kerja bagi para startup digital dan non-digital.

Sebagai salah satu kerangka kerja pengembangan startup ini, Telkom menciptakan upaya untuk menyaring startup melalui kompetisi startup digital dengan nama Indigo Apprentice Awards. Beberapa startup digital yang memenangkan kompetisi kemudian dibina sebagai incubatee di dalam inkubator bisnis serta mendapatkan dana pembiayaan awal bagi pengembangan produk. Dana pengembangan awal cuma-cuma atau yang seringkali disebut sebagai angel investment berasal dari Telkom dan beberapa angel investor lainnya. Para incubatee ini kemudian ditempatkan di dalam inkubator bisnis Telkom di Bandung Digital Valley atau di Jogjakarta Digital Valley. Startup yang berhasil melalui masa inkubasi dan mendapatkan modal dari Venture Capital (VC) kemudian direkrut di akselerator bisnis Telkom yang berlokasi di Jakarta (Jakarta Digital Valley). Tujuan dari penempatan startup digital ke dalam akselerator bisnis adalah untuk memastikan keberlanjutan startup serta mempersiapkan startup tersebut untuk mendominasi industri digital.

Kehadiran coworking space sendiri di dalam program penumbuhan startup digital dan nondigital yang digagas oleh Telkom adalah bentuk yang melengkapi keberadaan akselerator bisnis dan inkubator bisnis. Coworking space berperan dalam pemberian layanan secara gratis bagi startup digital yang tidak memiliki ruang kerja agar dapat bekerja dan beroperasi dengan fasilitas lengkap selayaknya sebuah startup dengan kantor pribadi.

Mengikuti kompetisi Indigo Apprentice Awards yang diselenggarakan oleh Telkom. Integrasi antara akselerator, inkubator bisnis, dan coworking space menjadi satu pola pengembangan bersifat strategis; karena pola semacam ini menjamin keberlanjutan sebuah startup melalui pembinaan startup digital agar berhasil dalam menjalani siklus bisnisnya.

\section{b. Model Pemerintah}

Di dalam dunia perkembangan bisnis startup, pemerintah juga turut berperan dengan menjalankan fungsi sebagai penyedia inkubator bisnis. Dalam hal ini, terdapat paling tidak empat entitas pemerintah yang membuka layanan inkubator bisnis, antara lain, Kementerian Perekonomian, Kementerian Perindustrian, Badan Pengkajian dan 
Penerapan Teknologi (BPPT), dan Kementerian Komunikasi dan Informatika (Kominfo). Namun, hal yang perlu menjadi catatan adalah ketiadaan koordinasi antarentitas pemerintah dalam upaya pengembangan inkubator bisnis; hal ini dapat dilihat dari ketiadaan forum bersama antarentitas pemerintah tersebut.

Kominfo dan inkubator bisnis dari BPPT dalam penelitian ini adalah unit analisis yang diteliti. Kominfo adalah penyedia inkubator bisnis bagi startup-startup di bidang informatika yang secara definitif bergerak pada aspek komunikasi; sedangkan BPPT adalah penyedia inkubator bisnis yang menaungi startup dari ragam industri berbasis teknologi. Terdapat perbedaan histori atas aspek inisiasi penumbuhan inkubator bisnis yang digagas oleh pemerintah jika dibandingkan dengan entitas yang lain. Pada kasus Kominfo dan BPPT, pembuatan inkubator bisnis berawal dari adanya kucuran dana yang semula hendak digunakan sebagai angel investment yang diberikan bagi startup potensial. Selanjutnya, kucuran dana ini ditransformasi penggunaannya menjadi kapital dalam pengembangan inkubator bisnis.

Upaya menjaring startup diselenggarakan melalui sosialisasi dan rekrutmen. Prosedur rekrutmen berbasis pada proses penilaian dan evaluasi yang diarahkan untuk mengukur dua aspek penting di dalam kualitas startup yakni product and people atau produk dan tim (manajerial). Kominfo dan BPPT memberikan layanan sumberdaya bisnis bagi para startup yang berada di bawah naungannya agar startup tersebut memiliki derajat sustainability yang tinggi. Secara integral, layanan ini juga digenapi dengan upaya Kominfo dan BPPT untuk menjalin kerjasama dengan beberapa pihak untuk mengembangkan kualitas para startup.

\section{c. Model Swasta}

Potensi yang besar di dalam dunia bisnis startup juga menarik perhatian sektor swasta. Pada saat ini terdapat sektor swasta asing dalam negeri atau swasta lokal dan sektor swasta asing yang mengembangkan inkubator bisnis dan coworking space. Misi utama dari pembangunan inkubator bisnis maupun coworking space secara umum bersandar pada kepentingan ekonomi yakni keuntungan bisnis yang dapat diraih.

Terdapat dua model bisnis di dalam inkubator bisnis yang disediakan oleh sektor swasta, yakni model bisnis pembagian kepemilikan saham dan joint-ventures. Model pembagian kepemilikan saham merupakan konsekuensi logis bagi para founder inkubator bisnis yang telah menyediakan berbagai sumberdaya bagi startup. Pembagian saham seringkali menjadi syarat dasar bagi startup untuk bisa masuk dan dibina oleh inkubator bisnis. Dalam hal ini, umumnya CEO inkubator bisnis memiliki sebagian kecil dari keseluruhan persentase saham dari startup yang berhasil dikembangkan. Sedangkan dalam model joint ventures, startup terkadang justru diposisikan sebagai unit R\&D dari perusahaan yang dimiliki oleh founder inkubator bisnis tersebut. Dalam kerangka kerja ini, model joint ventures adalah strategi yang efektif untuk membangun unit R\&D secara murah; dimana produk yang dibuat oleh suatu startup akan lebih mudah diakuisisi oleh perusahaan pemilik inkubator bisnis tersebut. Proses rekrutmen startup di dalam inkubator bisnis sendiri melalui prosedur yang cukup rumit. Pada awalnya, seleksi dilakukan dan kemudian diikuti dengan rangkaian evaluasi untuk menentukan startup pemenang.

Terdapat perbedaan yang cukup substansial dalam melihat inkubator bisnis yang dimiliki oleh swasta asing dan swasta lokal, salah satu perbedaan yang menonjol adalah level jaringan kerja yang dimiliki tiap pihak tersebut. Pihak swasta lokal dan swasta asing memiliki jaringan yang berada di dalam ranah bisnisnya; swasta lokal seringkali memiliki jaringan kerja lokal yang kuat bila dibandingkan dengan jaringan 
kerja internasional; sebaliknya, swasta asing seringkali memiliki jaringan kerja internasional yang lebih kuat bila dibandingkan dengan jaringan kerja lokal. Pada aspek coworking space, model bisnis yang dijalankan oleh sektor swasta sangat rekat pada corak kepentingan ekonomi yakni menjaring startup sebanyakbanyaknya untuk bekerja pada area kerja yang telah disediakan; mengingat semakin banyak keanggotaan startup pada satu coworking space akan mempengaruhi jumlah pendapatan yang diterima oleh si pemilik coworking space.

\section{d. Model Komunitas}

Komunitas dicirikan dengan solidaritas yang mekanis, artinya terdapat kesadaran secara kolektif diantara para individu untuk bersama, dimana kesadaran-kesadaran ini terbangun melalui interaksi sosial. Rasa kebersamaan yang kuat tersebut ditunjukkan dengan derajat kohesivitas yang begitu tinggi antarindividu di dalam komunitas. Merujuk pada hal ini, maka komunitas dapat dimaknai sebagai suatu unit atau kesatuan sosial yang terorganisasir dalam kelompok-kelompok dengan kepentingan bersama (communities of common interest), baik yang bersifat fungsional maupun yang bersifat teritorial. Melalui rasa kebersamaan yang kuat, seringkali komunitas menciptakan berbagai fungsi sosial ekonomis untuk dapat mencapai tujuan bersama. Dalam hal ini, beragam komunitas dengan basis ketertarikan berbeda di wilayah Jakarta, Bandung, dan Yogyakarta menciptakan inkubator bisnis maupun coworking space untuk mewadahi startup yang dimiliki oleh anggota komunitas tersebut.

Identitas yang mudah dikenali dari inkubator bisnis yang berbasis komunitas adalah keberagaman industri startup. Kemajemukan ini ditambah dengan kenyataan bahwa di beberapa daerah, inkubator bisnis adalah wujud kerjasama beberapa komunitas yang melebur ke dalam satu wadah. Selain itu, terdapat relasi yang lebih dialogis dan cenderung setara di antara para startup dan CEO. Dalam kerangka kerja ini, pembagian kepemilikan saham antara startup dan CEO seringkali tidak bersifat tegas namun dapat direkonstruksi melalui serangkaian diskusi informal. Hal ini dimungkinkan karena inkubator bisnis yang dijalankan oleh komunitas berukuran kecil sehingga sistem dan tata kelola organisasi yang dijalankan pun bersifat kompromistis. Hal inilah yang menyebabkan perubahan-perubahan dapat dengan mudah direspon melalui adaptasi cepat organisasi. Sistem perekrutan di dalam inkubator bisnis berbasis komunitas cenderung tidak sulit mengingat startup yang berada di dalam wadahnya merupakan anggota dari komunitas yang mereka ikuti.

\section{e. Model Universitas}

Saat ini, beberapa perguruan tinggi di Indonesia berupaya untuk menginternalisasi karakter entrepreneurship di dalam kehidupan akademik tiap mahasiswanya. Misi tersebut menginduk pada cita-cita bahwa perguruan tinggi tidak hanya mencetak pekerja yang kompeten, namun juga dapat menghasilkan seorang entrepreneur atau wirausaha. Misi ini membawa misi yang lebih luas dari sebuah perguruan tinggi yakni berkontribusi pada kemajuan suatu negara dengan meningkatkan jumlah populasi wirausaha. Konsep entrepereneurship belakangan bertransformasi dan dielevasi menjadi konsep sociopreneurship. Di dalam konsep sociopreneurship, seorang wirausaha tidak mendudukkan kepentingan pribadi sebagai nilai pokok, namun menempatkan kepentingan masyarakat sebagai target sentral. Dengan demikian, konsep sociopreneurship menjadi substansial, karena nilai-nilai kewirausahaan diintegrasikan dengan nilai-nilai altruistik yakni kemanfaatan sosial bagi masyarakat. Di sisi lain, perguruan tinggi juga memiliki cita-cita untuk dapat mewujudkan hasil penelitian dan output pengajaran sebagai instrumen riil yang dapat memecahkan permasalahan bangsa. 
Misi perguruan tinggi untuk membentuk mahasiswanya menjadi sociopreneur dimanifestasikan ke dalam pembentukan inkubator bisnis. Namun, inkubator bisnis juga menyimpan fungsi lain yakni sebagai media bagi perguruan tinggi untuk dapat mewujudkan hasil penelitian ilmiah para mahasiswanya agar dapat diimplementasikan secara nyata di tengah masyarakat. Dalam hal ini, inkubator bisnis dapat dimaknai sebagai perpanjangan tangan perguruan tinggi untuk membina mahasiswa yang memilki ide produk dan keinginan membangun startup.

Lokus penelitian ini terdiri dari tiga inkubator perguruan tinggi yang menjadi unit analisis yakni Universitas Multimedia Nusantara (UMN), Institut Teknologi Bandung (ITB), dan Universitas Gadjah Mada (UGM). Dari ketiga perguruan tinggi ini, secara umum proses perekrutan startup dimulai dari seleksi dan berakhir dengan evaluasi bertahap untuk menentukan startup yang akan dibina oleh perguruan tinggi. Penentuan besaran kepemilikan saham antara mahasiswa dan universitas sebagai pemilik inkubator bisnis secara umum sudah ditetapkan walaupun tidak menutup peluang bagi kedua belah pihak untuk mengalterasi angka tersebut melalui mekanisme yang kompromistis. Dari aspek relasi, ketiga perguruan tinggi juga membangun relasi dengan banyak pihak, namun secara umum menggunakan jaringan alumni sebagai basis signifikan pengembangan jaringan kerja.

\section{Analisa Efektivitas Inkubator Bisnis}

Merujuk pada penjelasan di atas, maka keenam determinan yakni, a) ragam layanan; b) infrastruktur; c) kondisi sosial; d) besaran jaringan; e) iklim kerja; f) tingkat keterlibatan inkubator bisnis dalam pengembangan startup, menjadi acuan dalam mengukur tingkat efektivitas inkubator bisnis dan inkubator bisnis hybrid (coworking space yang memiliki karakteristik menyerupai inkubator bisnis). Inkubator bisnis yang mewakili sektor pemerintah adalah Kementerian Komuniaksi dan Informatika (Kominfo) dan Badan Pengkajian dan Penerapat Teknologi (BPPT); sedangkan Telkom mewakili Badan Usaha Milik Negara (BUMN) yang tidak sepenuhnya mewakili rezim pemerintah yang bertujuan memenuhi tanggung jawab sosial, tetapi juga mengejar aspek keuntungan. Dari keseluruhan determinan, Kominfo dan BPPT berlokasi dalam satu dan dua kota, selain itu mereka hanya menaungi startup dengan basis produk di bidang teknologi. Layanan yang diberikan oleh kedua institusi ini hanya terbatas pada infrastruktur dan pelatihan manajerial serta bisnis dasar; walaupun Kominfo memberikan layanan yang lebih beragam seperti menjembatani startup dengan VC, penyediaan fasilitas pendaftaran hak kekayaan intelektual (intellectual property rights), dan penyediaan layanan pendampingan 1 mentor- 1 startup, namun di sisi lain, Kominfo hanya memiliki jaringan kerja yang sangat terbatas.

Telkom memiliki skala inkubasi bisnis yang jauh lebih besar bila dibandingkan dengan inkubator bisnis dari institusi pemerintah maupun inkubator bisnis dari entitas lain. Inkubator bisnis yang dimiliki oleh Telkom berlokasi di tiga kota. Telkom juga memiliki ragam layanan yang lebih banyak dan lengkap, terutama dari segi infrastruktur dan layanan pengembangan startup. Telkom memiliki laboratorium berisi peralatanperalatan yang dapat digunakan oleh startup untuk membangun prototype produk. Tidak hanya itu, Telkom juga menyediakan layanan mentorship dari aspek manajerial, bisnis, dan pengembangan image perusahaan. Fasilitas yang Telkom berikan dalam menghubungkan startup dengan VC maupun angel investor yang berperan efektif dalam meningkatkan eksposur startup kepada pemilik modal di level nasional maupun global, mengingat Telkom memiliki jaringan kerja (network) yang tersebar di level 
nasional maupun global. Dalam hal ini, Telkom secara khusus memelihara hubungan dekat dengan para VC dan angel investor, sehingga Telkom dapat menjalankan perannya sebagai hub untuk menghubungkan startup dan pemilik modal secara maksimal. Inkubator bisnis yang dimiliki oleh sektor pemerintah maupun BUMN secara umum memiliki iklim kerja yang berjarak dan tidak egaliter, walaupun hubungan antara startup dengan tim manajemen tetap dialogis, dimana inkubator bisnis tetap membuka kesempatan rutin bagi tumbuhnya komunikasi dan diskusi antara tim manajemen inkubator bisnis dengan startup.

Inkubator bisnis yang dimiliki oleh sektor swasta diwakili oleh Kolaborasi Kapital Indonesia (KKI), Conclave, dan Merah Putih Incorporated (MPI) juga menunjukkan pola inkubasi yang hampir sama di beberapa aspek. Kedua inkubator ini hanya berlokasi di satu kota, memiliki jaringan kerja yang terbatas, namun memiliki iklim kerja yang egaliter, dialogis, dan tidak berjarak. Perbedaan dari KKI, Conclave, dan MPI terletak pada jenis industri startup yang mereka naungi dan ragam layanan inkubasi yang diberikan. MPI hanya mau menaungi startup dengan produk industri digital, sedangkan KKI dan Conclave menaungi startup dari jenis industri manapun. Dari segi layanan inkubasi, KKI hanya memberikan pelatihan manajerial dan bisnis dimana pelatihan ini disediakan oleh startup yang berada di bawah satu manajemen, hal ini sesuai dengan platform kekeluargaan yang menjadi basis pelaksanaan program inkubasi di dalam KKI. Sedangkan, MPI dan Conclave tidak hanya memberikan layanan pelatihan manajerial dan bisnis, tetapi juga menyediakan kesempatan bagi para startup untuk terhubung dengan VC dan network yang lain. Meskipun demikian, network MPI dan Conclave sangat terbatas.

Inkubator bisnis yang berasal dari sektor pendidikan diwakili oleh Lembaga Pengembangan Inovasi dan Kewirausahaan
(LPIK) milik Institut Teknologi Bandung (ITB), Skystar Ventures milik Universitas Media Nusantara (UMN), Innovative Academy milik Universitas Gadjah Mada (UGM), dan Binus Creates Binus milik Universitas Bina Nusantara. Inkubator bisnis yang dimiliki oleh sektor pendidikan tinggi ini memiliki perbedaan corak di beberapa aspek. Perbedaanya adalah LPIK, Skystar Ventures, dan Innovative Academy hanya menerima startup yang produknya berbasis pada teknologi dan teknologi digital, sedangkan Binus Creates menerima startup dari beragam industri. Perbedaan yang lainnya Skystar Ventures, Innovative Academy, dan Binus Creates menyediakan beberapa pelatihan manajerial dan bisnis. Lebih dari itu, Skystar Ventures menyediakan seed funding bagi para startup, sedangkan LPIK menghubungkan startup dengan beberapa angel investor yang sebagian besar adalah alumni ITB. Innovative Academy menghubungkan startup dengan jaringan angel investor yang berasal dari alumni juga korporasi, dan Binus Creates membantu startup dalam mengurus dokumen legal. Perbedaan dari segi jaringan kerja, hanya Innovative Academy, Skystar Ventures, dan Binus Creates memiliki jaringan kerja dengan beberapa entitas. LPIK tidak menjaring network dengan entitas manapun. Perbedaan yang menarik dari sisi iklim kerja yang terbangun di dalam inkubator bisnis sektor pendidikan tersegregasi menjadi dua kubu; LPIK memiliki iklim kerja yang dialogis dan berjarak, sedangkan Skystar Ventures, Innovative Academy, and Binus Creates memiliki hubungan yang dialogis dan tidak berjarak.

Analisismodelinkubasibisnis diatas dapat dilihat bahwa Telkom memiliki inkubator bisnis yang lebih efektif bila dibandingkan dengan inkubator bisnis lainnya. Inkubator bisnis yang dimiliki oleh Telkom memenuhi determinan ragam layanan, infrastruktur, kondisi sosial, jaringan kerja, dan tingkat keterlibatan yang tinggi terhadap pengembangan startup; 
walaupun perlu digarisbawahi bahwa iklim kerja yang terbangun di dalam inkubator bisnis Telkom masih berjarak, kendati dialogis.

\section{Analisa Tata Kelola GVC Bisnis Digital di Indonesia}

Pada konteks governance dalam GVC, pola relasi antara inkubator dengan startup menunjukkan kecenderungan mengutamakan dialog dengan prinsip yang egaliter. Dari kelima tipe tata kelola GVC, pola relasi internal inkubator bisnis digital yang lebih condong ke arah yang egaliter atau minim hierarki mengindikasikan terbentuknya tipe yang relational. Model relational ada pada keadaan dimana terdapat interaksi yang lebih kompleks antaraktor (pembeli dan penjual), atau dalam konteks tulisan ini: antara inkubator dengan startup. Interaksi yang terjalin ini kemudian menciptakan ketergantungan antara kedua belah pihak.

Interaksi antaraktor itu kemudian dapat dilihat dalam kerangka kepercayaan atau reputasi maupun keluarga. Reputasi atau kepercayaan dan ikatan keluarga dapat menjadi perekat ketika relasi yang terbangun berada pada spasial yang jauh atau tersebar. Kepercayaan atau trust kemudian menjadi salah satu kunci untuk menjelaskan pola relasional ini. Dengan dasar ini, hubungan antara inkubator dengan startup tidak serta merta terputus begitu saja. Hal ini dikarenakan adanya relasi yang sudah terjalin di antara keduanya. Relasi tersebut dapat dilihat pada skema mentoring yang diinisiasi oleh inkubator. Selain itu, ditemukan pula upaya transfer pengetahuan dari inkubator kepada startup. Relasi lain terbentuk melalui upaya yang dilakukan inkubator untuk membukakan jaringan modal (misal menjaring angel venture) serta akses pasar.

Meskipun berbagai model pengelolaan industri berbasis inovasi tersebut menunjukkan gejala yang cenderung mengarah pada model relational, namun pada derajat tertentu dapat dilihat berlakunya separation of powers, khususnya dalam relasi vertikal antara pengelola inkubator dan startup. Pemisahan kekuasaan ini terbaca dari adanya pembeda peran antara pengelola inkubator dengan startup yang sangat jelas. Inkubator menjalankan kekuasaan legislatifnya, melalui penentuan standar produk yang akan dihasilkan startup, dan standar yang digunakan pada umumnya adalah daya jual dari produk yang dihasilkan startup. Jika produk yang dirancang startup dinilai memenuhi kriteria layak dan berpotensi jual, maka dukungan inkubator akan menguat. Sebaliknya, inkubator akan melepaskan startup jika produk yang dihasilkannya tidak menjanjikan keuntungan atau minimal mempunyai prospek penjualan yang tinggi. Pada level ini dapat dilihat posisi inkubator yang lebih menentukan dibandingkan dengan startup. Penerapan standar pada level eksekutif dilakukan melalui proses mentoring dan workshop, dengan durasi yang berbeda-beda antar inkubator. Setiap inkubator merancang modul-modul pelatihan dan mengelola proses mentoring sesuai dengan kebutuhan dan sumber daya finansial yang dimilikinya. Demikian juga di level kekuasaan yudisial, inkubator yang memegang kendali untuk memonitor performa atau penerapan standar dalam mekanisme proses produksi.

Pengamatan atas implementasi tiga level kekuasaan yaitu legislatif, eksekutif, dan yudikatif, terlihat adanya dominasi inkubator terhadap startup. Inkubator menjadi penentu awal apakah startup dapat melanjutkan ke tahap selanjutnya (baca: berkompetisi di pasar) atau tidak. Bagi startup yang prospektif, koneksi kepada investor tentu akan terbuka lebar. Bahkan untuk model inkubasi yang dikelola PT Telkom, startup yang lolos dari masa inkubasi akan dibina lebih lanjut melalui program akselerasi. Meskipun nuansa "dominasi" inkubator terhadap startup yang masuk didalamnya cukup kental, namun dengan model dialog yang sifatnya cenderung dialogis menjadikan relasi antara inkubator dengan startup menjadi jauh lebih cair. 
Terkait dengan hal tersebut, ada perbedaan mendasar antara model inkubasi yang dikelola pemerintah, universitas dan komunitas. Melalui model inkubasi yang diterapkan oleh swasta maupun BUMN (PT Telkom dalam hal ini dapat dikatakan mempunyai orientasi pasar yang jelas, sehingga ada kemiripan dengan model swasta). Inkubasi oleh pemerintah, universitas dan komunitas cenderung mempunyai standar dan orientasi yang lebih terkait dengan aspek pengembangan awal produk, mulai tahap ide sampai produk siap diluncurkan, serta mengasah kultur kewirausahaan dari startup. Inkubasi yang dilakukan lebih mengarah pada upaya mengkaitkan startup dengan calon investor.

Inkubasi yang dilakukan oleh swasta dan BUMN cenderung lebih market oriented. Misalnya PT Telkom, pilihan terhadap startup serta produk startup sangat dipengaruhi oleh identifikasi kebutuhan pasarnya. Produk aplikasi startup yang diinkubasi PT Telkom diproyeksikan untuk mengisi pasar yang sudah dimiliki oleh PT Telkom. Sehingga jika potensi startup tersebut besar, PT Telkom akan sekaligus menjadi investor, dan bahkan membuka peluang bagi masuknya investor untuk menyuntik modal bagi startup yang berada dalam area inkubasi dan akselerasi perusahaan ini.

Adanya orientasi pasar yang kuat ini menjadi pembeda tegas antara inkubasi yang dikembangkan oleh swasta dan BUMN dengan inkubasi yang diterapkan dalam tiga model yang lain. Orientasi pada kebutuhan pasar ini pada gilirannya akan berpengaruh inkubator menjalankan peran legislatif, eksekutif, dan yudikatif dalam konteks tata kelola dalam GVC. Dengan kata lain, data menunjukkan adanya kecenderungan dominasi pengelola inkubator terhadap startup lebih kuat dalam model inkubasi yang diterapkan oleh swasta maupun BUMN dibandingkan dengan tiga model inkubasi lainnya. Adanya kecenderungan dominasi dalam industri berbasis inovasi dari berbagai kasus yang dijumpai dalam riset ini menjadikan model relasional sedikit bergeser ke arah model yang captive.

\section{Apakah Godfather Dibutuhkan dalam Mengembangkan Inkubator Bisnis yang Inovatif?}

Poin yang dapat disimpulkan dengan menggunakan kerangka Godfather on Innovations adalah bahwa dalam industri berbasis inovasi, diperlukan aktor kuat yang kurang lebih mempunyai kapasitas sebagaimana Godfather yang dibayangkan oleh Smith. Artinya, dalam derajat tertentu kecenderungan pola relasi kuasa dalam industri berbasis inovasi yang mengarah pada tipe campuran antara model relational dengan model captive dalam derajat tertentu memang diperlukan. Terlebih lagi dalam konteks dimana industri tersebut masih dalam tahapan awal sebagaimana yang ada di Indonesia. Hal ini berarti bahwa industri berbasis inovasi dan teknologi does needs a Godfather untuk dapat tumbuh dan berkembang.

Hasil dari semua inkubator bisnis yang digunakan sebagai unit analisa, dapat dijabarkan bahwa dinamika governance dalam konteks relasi vertikal antara pengelola inkubator dengan startup menunjukkan adanya campuran model relational di satu sisi dan kecenderungan model captive di sisi lain. Namun, dalam konteks relasi antara pengelola inkubator dengan sesama pengelola inkubator menunjukkan hal yang berbeda. Relasi antarpengelola inkubator ada kecenderungan untuk berjalan sendiri-sendiri dan tidak terkait satu sama lain. Antara model berbasis komunitas dengan model swasta dan BUMN misalnya, titik temu antara kedua model ini terbatas pada "pinjam-meminjam" sumber daya. Sebagai contoh, mentor dalam model komunitas diminta menjadi pembicara dalam workshop yang diselenggarakan model BUMN atau swasta. Selain tampak berjalan sendirisendiri, tim peneliti juga menangkap logika 
nir-kompetisi antar pengelola inkubator. Kemungkinan besar, hal ini disebabkan karena industri yang dijalankan masih sangat muda (rata-rata pengelola inkubator baru berdiri 3 bulan - 2 tahun) dan pada saat yang sama, pasar yang ada masih sangat luas dengan pemain yang masih sedikit.

Nuansa kompetisi masih cenderung rendah untuk pengelola inkubator di Yogyakarta. Hal ini terjadi karena ada kebebasan bagi startup untuk mengikuti proses inkubasi di beberapa tempat sekaligus, meskipun dengan inovasi yang berbeda. Istilah " $4 \mathrm{~L}$ : Loe lagi Loe Lagi" menggambarkan fenomena pemain yang secara kuantitatif masih terbatas, sehingga dimanapun inkubasinya, sumber daya manusia yang menjadi startup kurang lebih sama. Selain itu, perbedaan nilai antara pengelola inkubator satu dengan yang lain juga menjelaskan mengapa mereka berjalan sendirisendiri. Sebagai contoh, nilai yang dimiliki oleh pengelola inkubator berbasis komunitas pada umumnya lebih mengarah pada upaya pengembangan ide dan jiwa kewirausahaan. Saling berbagi ide dan pengalaman menjadi nilai penting yang dipertahankan. Sementara, untuk model swasta maupun BUMN, nilai acuannya cenderung berorientasi pada pasar. Hal ini menjadikan model komunitas tampak enggan untuk berkolaborasi dengan model swasta dan BUMN.

\section{Kesimpulan}

Tulisan ini telah mendiskusikan efektivitas dan pola relasi kekuasaan baik secara internal di dalam inkubator antara pengelola dan startup maupun secara eksternal antara sesama pengelola inkubator. Dari sisi efektivitas pengelolaan inkubator bisnis digital dapat disimpulkan bahwa pengelola dari BUMN yang dalam penelitian ini diwakili oleh PT Telkom memiliki inkubator bisnis yang lebih efektif bila dibandingkan dengan inkubator bisnis lainnya. Inkubator bisnis yang dimiliki oleh PT Telkom memenuhi determinan ragam layanan, infrastruktur, kondisi sosial, jaringan kerja, dan tingkat keterlibatan yang tinggi terhadap pengembangan startup; walaupun perlu digarisbawahi bahwa iklim kerja yang terbangun di dalam inkubator bisnis Telkom masih berjarak, kendati dialogis.

Secara umum setiap inkubator bisnis memiliki kesamaan dalam cita meningkatkan jiwa entrepreneurship dan mengembangkan startup. Selain itu, layanan yang diberikan tiap inkubator bisnis, model bisnis, cara penjaringan startup pun memiliki keseragaman. Namun, perbedaan yang cukup mencolok terdapat pada aspek jaringan kerja. Inkubator bisnis memiliki jaringan kerja di level internasional, sedangkan inkubator bisnis yang lain memiliki jaringan kerja hanya di level nasional maupun level lokal. Inkubator bisnis yang dimiliki oleh pemerintah dan universitas tidak memiliki jaringan global yang luas, namun PT Telkom Tbk dan beberapa entitas dari sektor swasta justru memiliki jaringan global yang cukup besar. Luasnya jaringan global ini ditentukan oleh komitmen dan koneksi founder maupun tim manajemen dari inkubator bisnis tersebut.

Perbedaan juga dapat dilihat pada keyakinan tiap inkubator bisnis dalam menentukan jenis industri dari startup yang ingin dinaunginya. Beberapa inkubator bisnis ingin menaungi startup dengan ragam industri yang berbeda, namun seringkali keinginan ini tidak didukung oleh sumberdaya inkubator bisnis yang memadai. Pembinaan pada startup dengan ragam industri membutuhkan resources yang besar, sebab inkubator bisnis harus mampu merespons kebutuhan dan tantangan tiap startup dengan kondisi tiap industri yang memiliki nature dan kebutuhan berbeda. Alasan inilah yang membuat beberapa inkubator bisnis lainnya memilih fokus pada satu ranah industri.

Pola relasi antara inkubator dengan startup daalm konteks governance dalam GVC menunjukkan kecenderungan ke arah pola dialogis dan egaliter. Pola hubungan ini mengarah pada model governance yang 
relational dan berlangsung secara kompleks, sehingga terjalin ketergantungan antara kedua belah pihak. Hal ini kemudian membuat startup membutuhkan Godfather -yang merupakan aktor personal maupun institusi. Godfather mempunyai kapasitas-kapasitas tertentu yang dapat digunakan untuk memastikan inovasi dapat berjalan.

Terdapat enam komponen dalam ekosistem startup yang perlu diperhatikan, yaitu: pasar, modal, sumber daya manusia, kultur, infrastruktur, dan regulasi. Sejauh ini di Indonesia, baru faktor pasarlah yang sudah memadai. Sementara lima komponen lainnya masih harus dikembangkan. Dalam pengembangan ini, pemerintah dapat berperan sebagai enabler, dimana pemerintah memposisikan diri sebagai penyedia sumber daya dan infrastruktur yang relevan dengan upaya menumbuhkan bisnis startup, termasuk di dalamnya penyusunan regulasi yang dapat mengakselerasi bisnis industri TI di Indonesia. Peran ini dianggap lebih tepat dibandingkan dengan pemerintah berperan sebagai leader karena keterbatasan sumber daya manusia dan finansial pemerintah, ataupun sebagai user karena hal ini dapat mengubah kondisi pasar TI Indonesia yang sudah memadai.

\section{Daftar Pustaka}

Admin. 9 Maret 2015, Pemerintah Indonesia Menyiapkan Dana 12 Trilliun untuk Startup Indonesia. (Online). (http://ideaconnect. ugm.ac.id/news/site/view/136/pemerintahindonesia-menyiapkan-dana-12-trilliununtuk-startup-indonesia/2, diakses Juli 2015)

Allen, D.N., McCluskey, R., (1990). Structure, Policy, Services and Performance in The Business Incubator industry. Entrep. Theory Pract. 15 (2), 61 - 77.

Allen, D.N., Rahman, S., (1985). Small Business Incubators: A Positive Environment for Entrepreneurship. J. Small Bus. Manage., $12-24$.
Amin, A., and N. Thrift (1992) 'NeoMarshallian Nodes in Global Networks', InternationalJournal of Urban and Regional Research (16)

Asheim, B. (1996). Industrial Districts as "Learning Regions": a Condition for Prosperity', European Planning Studies, $4(4)$

Boediman, Andi S. (2015). Tujuh Pondasi Awal untuk Membangun Ekosistem Startup di Indonesia. (Online). (https://id.techinasia. com/pondasi-awal-ekosistem-startupindonesia/, diakses 27 Oktober 2015)

Bøllingtoft, A., \& Ulhøi, J. P. (2005). The Networked Business Incubator - Leveraging Entrepreneurial Agency?. Journal of Business Venturing. Vol. 20 No. 2, pp. 265-290.

Coe, N.M., P.F. Kelly and H.W.C. Yeung. (2007) Economic Geography: A Contemporary Introduction. Oxford: Blackwell.

Cohen, W. M., \& Levinthal, D. A. (1990). Absorptive Capacity: A New Perspective on Learning and Innovation. Administrative science quarterly. Vol. 35 No. 1, pp. 128-152.

Dallago, B. (2002). Corporate governance and governance paradigms. East West Journal of Economics and Business. Vol. 5 No. 2, pp. 173-196.

Gerrefi, Gary and John Humphrey. (2005). "The Governance of Global Value Chains", Review of International of Political Economy. (Online) (http://www.fao.org/fileadmin/user_ upload/fisheries/docs/GVC_Governance. pdf, diakses 1 Oktober 2015).

Glaeser, E. L., \& Kerr, W. R. (2009). Local Industrial Conditions and Entrepreneurship: How Much of The Spatial Distribution Can We Explain?. Journal of Economics \& Management Strategy. Vol. 18 No. 3, pp. 623-663.

Hudson, R. (1999). The Learning Economy, The Learning Firm and The Learning Region: A Sympathetic Critique of the Limits to Learning'. European Urban and Regional Studies. Vol. 6 No. 1. 
Inkubator Industri Informatika. (2015). Inkubator Industri Informatika. (Online). (http://www. aptika.kominfo.go.id/index.php/berita/23inkubator-industri-informatika, diakses 30 Oktober 2015)

Joffe, Benjamin. (2012). Ecosystem 101: The Six Necessary Categories to Build the Next Silicon Valley, Techcrunch News, September 1, 2012 (Online) (http://techcrunch. com/2012/09/01/ecosystem-101-the-sixnecessary-categories-to-build-the-nextsilicon-valley/, diiunduh 27 Oktober 2015)

Kemenkominfo. (2014). Ekosistem Startup di Indonesia: Di Mana Kita Sekarang \& Ke Mana Kita Bisa Melangkah, Makalah. Disusun oleh Tim Direktorat Pemberdayaan Industri Informatika, Direktorat Jenderal Aplikasi Informatika, Kementerian Komunikasi dan Informatika.Kaplinsky, R. dan Morris, M.(2012). A handbook for value chain research. Institute of Development Studies.

Kimball E. Bullington John V. Mullane. (2001). “Supplying Entrepreneurial Ventures: Lessons from Information Technology Companies". Management Decision. Vol. 39 Iss 1 , pp. $57-63$

Kompas.com. (2015a). Balon Google Penyebar Internet Masuk Indonesia. (Online). (http:// lipsus.kompas.com/topikpilihanlist/3794/1/ balon.google.penyebar.internet.masuk. indonesia, diakses Agustus 2015)

Kompas.com. (2015b). Mengudara di Indonesia, Balon Google Bisa Tertabrak Pesawat. (online). (http://tekno.kompas.com/ $\mathrm{read} / 2015 / 10 / 29 / 13430067 / M e n g u d a r a$. di.Indonesia.Balon.Google.Bisa.Tertabrak. Pesawat, diakses Agustus 2015).

Lalkaka, Rustam. (2002). Technology Business Incubators to Help Build an Innovationbased Economy. Journal of Change Management. Vol. 3 No. 2, pp. 167-176, DOI: 10.1080/714042533

Lane, P. J., Koka, B. R., \& Pathak, S. (2006). The Reification of Absorptive Capacity: A Critical Review and Rejuvenation of The
Construct. Academy of management review. Vol. 31 No. 4, pp. 833-863.

Lazonick, W. (1993). Business Organization and The Myth of The Market Economy. Cambridge: Cambridge University Press.

Löwik, S. (2013). Micro-foundations of Absorptive Capacity. A study on Knowledge Processes for Innovation in SMEs. Dissertation. The Netherlands: University of Twente.

Lyons, T.S., (2000). Building Social Capital for Sustainable Enterprise Development in Country Towns and Regions: Successful Practices from the United States. Paper presented at the First National Conference on the Future of Australia's Country Towns, LaTrobe University, Center for Sustainable Regional Communities, Australia. June 29 - 30.

MacKinnon, D., A. Cumbers and K. Chapman. (2002). Learning, Innovation and Regional Development: A Critical Appraisal of Recent Debates. Progress in Human Geography. Vol. 26 No. 3.

Martin, R. (2000). Institutional Approaches in Economic Geography, in: Sheppard, E. and T.J. Barnes (eds) A Companion to Economic Geography. (Malden, MA: Blackwell, 2002) Morgan, K. (1997). The Learning Region: Institutions, Innovation and Regional Renewal. Regional Studies. Vol. 31 No. 5.

OECD. (2007). Innovation and Growth, Rationale For an Innovation Strategy. (Online). (http:// www.oecd.org/science/inno/39374789.pdf., iunduh 27 Oktober 2015)

O'Neal, T. (2005). Evolving a successful universitybased incubator: Lessons learned from the UCF technology incubator. Engineering Management Journal. Vol. 17 No. 3, pp. 11-25.

O'Sullivan, M. (2000). The Innovative Enterprise and Corporate Governance. Cambridge Journal of Economics. Vol. 24 No. 4, pp. 393416.

Peters, L., Rice, M., \& Sundararajan, M. (2004). The role of incubators in the entrepreneurial process. The Journal of Technology Transfer. Vol. 29 Issue 1, pp. 83-91. 
Phan, P. H., Siegel, D. S., \& Wright, M. (2005). Science Parks and Incubators: Observations, Synthesis and Future Research. Journal of Business Venturing. Vol. 20 Issue 2, pp. 165-182.

Porter, M. (1996). Competitive Advantage, Agglomeration Economies, and Regional Policy. International Regional Science Review. Vol. 19 Issue 1, pp. 85-94.

Porter, M. (1998a). Clusters and the New Economics of Competitiveness. Harvard Business Review. (December) pp. 77-90.

Porter, M. E. (2000). Location, Competition, and Economic Development: Local Clusters in a Global Economy. Economic Development Quarterly. Vol. 14 Issue 1, pp. 15-34.

Pratomo, Gito Yudha. (2015). Tiongkok Siapkan Rp. 82 Triliun untuk Startup. CNN Indonesia. (Online). (http://www.cnnindonesia.com/ teknologi/20150116190821-185-25262/ tiongkok-siapkan-rp-82-triliun-untukstartup/. Edisi Sabtu, 17/01/2015, diunduh 30 Oktober 2015).

Priambada, Adjie. (2011). Mencari Tahu Kekuatan dan Kelemahan Ekosistem Startup Indonesia. (Online). (https://dailysocial. net/post/mencari-tahu-kekuatan-dankelemahan-ekosistem-startup-indonesia, diakses 27 Oktober 2015)

Rice, M. P. (2002). Co-production of Business Assistance in Business Incubators: an Exploratory Study. Journal of Business Venturing. Vol. 17 Issue 2, pp.163-187.

Rocha, H. O. (2004). Entrepreneurship and Development: The Role of Clusters. Small Business Economics. Vol. 23 Issue 5, pp. 363-400.

Sammarra, A., \& Biggiero, L. (2008). Heterogeneity And Specificity Of Inter-Firm Knowledge Flows In Innovation Networks. Journal Of Management Studies. Vol. 45 Issue 4, pp. 800-829.

Severino, Rodolfo C. (2002). Government's Role In Information Technology (Edited transcript of the closing remarks of Rodolfo
C. Severino, Secretary-General of the Association of Southeast Asian Nations, at the ASEAN Executive Seminar on e-Government Singapore, 19 November 2002). (Online). (http://www.asean.org/ resources/2012-02-10-08-47-56/speechesstatements-of-the-former-secretariesgeneral-of-asean/item/government-s-rolein-information-technology, diakses 27 Oktober 2015)

Sherman, H., Chappell, D.S. (1998). Methodological Challenges in Evaluating Business Incubator Outcomes. Econ. Dev. Q. 12 (4), $313-321$.

Smilor, R.W., Gill, M.D. (1986). The New Business Incubator. Linking Talent, Technology, Capital, and Know How Lexington Books, Massachusetts, Toronto.

Smith, DJ (2007), The Politics of Innovation: Why Innovations Need a Godfather. doi:10.1016/j.technovation.2006.05.001

Spinuzzi, C. (2012). Working Alone Together Coworking as Emergent Collaborative Activity. Journal of Business and Technical Communication. Vol. 26 Issue 4, pp. 399-441.

Tushman, M. L. (1977). Special Boundary Roles in the Innovation Process. Administrative Science Quarterly. Vol. 22 No. 4, pp. 587-605

United Kingdom Business Incubation (UKBI). (2004). The National Business Incubation Framework Summary Report. (Online). (www.ukbi.co.uk, diakses 1 April 2015).

Verheul, I., Wennekers, S., Audretsch, D., \&Thurik, R. (2001). An Eclectic Theory of Entrepreneurship: Policies, Institutions And Culture (No. 01-030/3). Tinbergen Institute Discussion Paper.

Volberda, H. W., Foss, N. J., \& Lyles, M. A. (2010). Perspective-Absorbing the Concept of Absorptive Capacity: How to Realize its Potential in The Organization Field. Organization Science. 21(4), 931-951.

Wever, E., \& Stam, E. (1999). Clusters of High Technology SMEs: the Dutch case. Regional Studies. 33(4), 391-400. 
Wolfe, D. A., \& Bramwell, A. (2008). Innovation, creativity and governance: Social Dynamics of Economic Performance in City-Regions. Innovation, 10(2-3), 170-182.

\section{Daftar Wawancara:}

Wawancara dengan Agung Asmawedha Kepala Manager Operasional Bandung Digital Valley, tanggal 10 Juni 2015.

Wawancara dengan Andi Saptari, Founders Co\&Co; Moh Andi Aulia, Founders Co\&Co; Hendra Araji, Relations Manager Co\&Co; tanggal 9 Juni 2015.

Wawancara dengan founder Conclave Randy, tanggal 9 Juni 2015.

Wawancara dengan Kepala BIT, Mohammad Hamdani, tanggal 12 Juni 2015.
Wawancara dengan Manager MPI, Mercy, tanggal 11 Juni 2015.

Wawancara dengan Manager Partnership and Alliance Management, Arief Rakhmatsyah, tanggal 9 Juni 2015.

Wawancara dengan San Karya, Manager MIC BINUS University, tanggal 10 Juni 2015.

Wawancara dengan Sang Kompiang Wiriawan, Kepala Sub Direktorat Inkubasi UGM, tanggal 3 Juni 2015.

Wawancara dengan Selliane Halia Ishak, Kasubdit Industri Perangkat Lunak KOMINFO RI, tanggal 9 Juni 2015.

Wawancara dengan Sigit Puji Santosa, Kepala Divisi Inkubasi dan Bisnis LPIK ITB, tanggal 11 Juni 2015.

Wawancara dengan Yovita Surianto, Program Manager Skystar Ventures, tanggal 12 Juni 2015. 